\title{
Clustered randomised trial of an intervention to improve the management of asthma: Greenwich asthma study
}

\author{
U N Premaratne, J A C Sterne, G B Marks, J R Webb, H Azima, P G J Burney
}

\begin{abstract}
Objectives To evaluate the effectiveness of an asthma resource centre in improving treatment and quality of life for asthmatic patients.

Design Community based randomised controlled trial.

Setting 41 general practices in Greenwich with a practice nurse.

Subjects All registered patients aged $15-50$ years. Intervention Nurse specialists in asthma who educated and supported practice nurses, who in turn educated patients in the management of asthma according to the British Thoracic Society's guidelines. Main outcome measures Quality of life of asthmatic patients, attendance at accident and emergency departments, admissions to local hospitals, and steroid prescribing by general practitioners.

Results Of 24400 patients randomly selected and surveyed in 1993, 12238 replied; 1621 were asthmatic of whom 1291 were sent a repeat questionnaire in 1996 and 780 replied. Of 24400 patients newly surveyed in 1996, 10783 (1616 asthmatic) replied. No evidence was found for an improvement in asthma related quality of life among newly surveyed patients in intervention practices compared with control practices. Neither was there evidence of an improvement in other measures of the quality of asthma care. Weak evidence was found for an improvement in quality of life in intervention practices among asthmatics registered with study practices in 1993 and followed up in 1996. Neither attendances at accident and emergency departments nor admissions for asthma showed any tendency to diverge in intervention and control practices over the study period. Steroid prescribing rates rose steadily during the study period. The average annual increase in steroid prescribing was $3 \%$ per year higher in intervention than control practices $(95 \%$ confidence interval $-1 \%$ to $6 \%, \mathrm{P}=0.10$ ).
\end{abstract}

Conclusions This model of service delivery is not effective in improving the outcome of asthma in the community. Further development is required if cost effective management of asthma is to be introduced.

\section{Introduction}

Initiatives to improve the care of asthmatic patients have included guidelines for treatment and educational packages for patients. ${ }^{12}$ Primary care plays a key role in the management of asthma in the United Kingdom, and the government has introduced incentives for doctors to run specialist clinics to treat chronic conditions including asthma. ${ }^{3}$

Nurses in general practice are increasingly involved with managing chronic disease and implementing asthma guidelines. Non-randomised studies suggest that nurse run asthma clinics reduce morbidity and improve quality of life in asthmatic patients. ${ }^{45}$
Guidelines and self management plans vary. ${ }^{6}$ Randomised trials suggest that they can improve outcome,${ }^{7-10}$ although success has not always been replicated. ${ }^{11}{ }^{12}$ The introduction of guidelines for asthma in non-training general practices in inner cities has been shown to increase recording of inhaler technique and to improve the quality of prescribing. ${ }^{13}$

In 1993 an asthma resource centre was established in Greenwich District Hospital to reduce morbidity from asthma. This centre was staffed by a secretary and three nurse specialists in asthma under the supervision of a respiratory physician (JRW) to facilitate the community wide implementation of the British Thoracic Society's guidelines for asthma. We evaluated this intervention.

\section{Subjects and methods}

\section{Stratification}

All general practices in the Greenwich health district with practice nurses and space for a clinic were eligible. Practices that shared a nurse were grouped for randomisation. Practices were stratified by whether the practice nurse had attended an asthma training course, ranked according to nursing hours available and social deprivation score, paired on the basis of this final order, and randomly allocated using random numbers to either intervention or control groups within pairs (fig 1).

\section{Role of nurse specialists}

Six teaching sessions on core elements of asthma care were offered to all practice nurses in the intervention practices. The nurse specialists then visited the practices, helped the practice nurses to organise the clinics in keeping with their teaching, assisted them in improving the management of their patients, and gradually devolved responsibility to them. The nurse specialists also ensured continuity of care in practices when practice nurses left.

\section{Methods}

We conducted two cross sectional surveys of patients registered with the practices; a baseline survey at the start of the intervention in September 1993 and a resurvey at the end in September 1996. The survey ended 1 year later than specified in the protocol to allow more time for the intervention. For each survey, we randomly selected 24400 patients aged $15-50$ years from the general practice lists (see website). We excluded patients from the second survey who had been selected for the first survey. Additionally, we resurveyed asthmatic patients identified during the baseline survey at the end of the study (fig 2).

The survey methods are described elsewhere..$^{14} \mathrm{We}$ asked all patients to complete a screening questionnaire. Those who reported during the past 12 months being woken with shortness of breath, an asthma

\author{
Department of \\ Public Health \\ Sciences, King's \\ College London, \\ Capital House, \\ London SE1 3QD \\ U N Premaratne, \\ specialist registrar \\ J A C Sterne, \\ senior lecturer \\ $\mathrm{H}$ Azima, \\ assistant statistician \\ P G J Burney, \\ professor \\ Institute of \\ Respiratory \\ Medicine, \\ University of \\ Sydney, New South \\ Wales 2006, \\ Australia \\ G B Marks, \\ research fellow \\ Asthma Resource \\ Centre, Greenwich \\ District Hospital, \\ Greenwich, London \\ SE10 9HE \\ J R Webb, \\ consultant physician \\ Correspondence to: \\ Professor Burney \\ Peter.burney@kcl. \\ ac.uk
}

BMJ 1999;318:1251-5

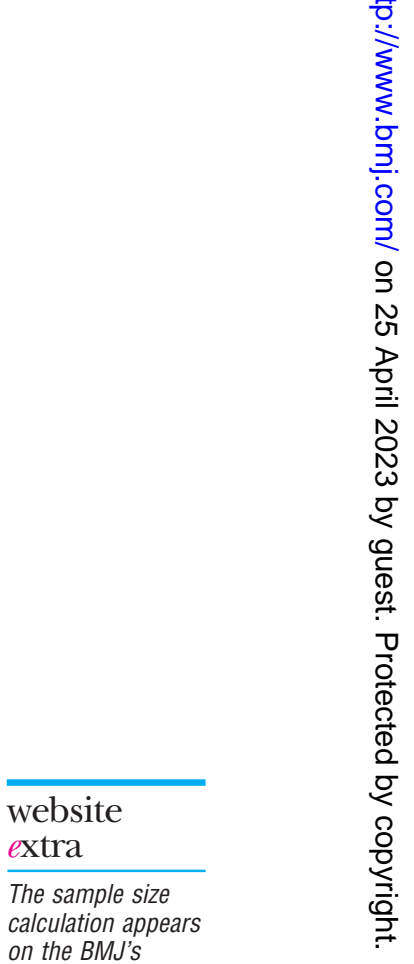

website

www.bmj.com 


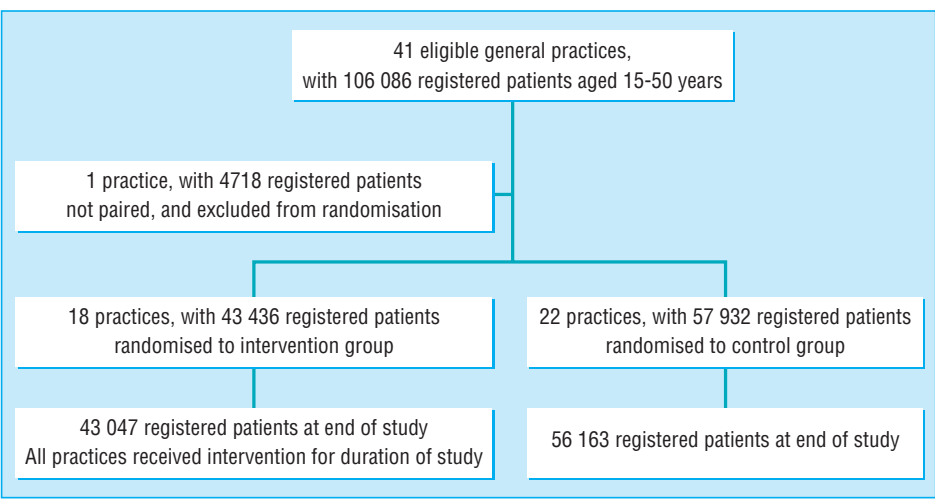

Fig 1 Randomisation of general practices

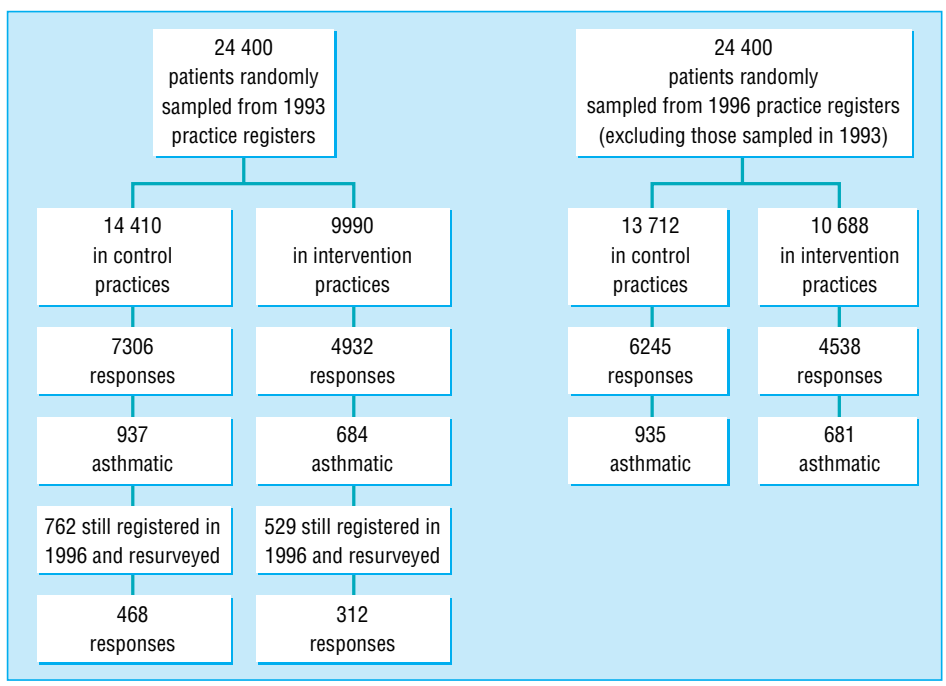

Fig 2 Surveys of patients used to evaluate intervention

attack, or treatment for asthma, were asked to complete a longer questionnaire. This included an asthma quality of life measure ${ }^{15}$ and other questions on asthma care experienced by the patient.

\section{Outcome measures}

The square root of the quality of life score is approximately normally distributed,$^{15}$ and we specified that the primary outcome would be differences in mean square root quality of life between intervention and control practices.

We also measured attendance at the accident and emergency departments of the Greenwich District Hospital and Brook Hospital with problems related to asthma, admission to these hospitals with a primary diagnosis of asthma, and changes in the prescribing patterns of the general practitioners. We retrieved accident and emergency attendances ${ }^{16}$ and hospital admissions related to asthma from the hospital information support system. We obtained quarterly prescribing data from the health authority. Drugs used to treat asthma in the relevant age groups were categorised as bronchodilators, steroids, or cromoglycates, and we applied a weight to give a total standard dose for any prescription quantity. We used these to derive the total doses of drugs prescribed by each practice. The primary outcome for this analysis was the logarithm of the ratio of total steroids to the practice population aged $15-50$ years.
Models

We used random effects models (allowing a different mean response in each practice) to assess differences in mean square root quality of life between intervention and control practices. Because we randomised a comparatively small number of practices, models controlled for potential confounding factors including mean square root quality of life measured in the first survey, pairing in the randomisation, sex and age of the patient, and other characteristics of the practices. For binary outcomes, we used generalised estimating equations ${ }^{17}$ (analogous to logistic regression) to assess differences between intervention and control practices, allowing for similarity between practices. For the aggregated data sources, we evaluated the effect of the intervention by looking for a linear change in the difference between intervention and control practices over time, also using random effects models. We performed analyses with STATA (Stata, College Station, TX).

Approval was given by the Greenwich research ethics committee.

\section{Results}

All 45 general practices in Greenwich agreed to take part but four were ineligible. Overall, 101086 patients aged 15-50 years were registered with the study practices at the start of the study and 99210 were registered at follow up. Three sets of practices were grouped together because they shared a practice nurse, and all were randomised to the control group. The 18 intervention practices contained $40.9 \%$ of the subjects at baseline and $43.8 \%$ postintervention. Overall, $12238(50.2 \%)$ responsed at baseline and 10783 $(44.2 \%)$ at follow up. Excluding those known to be no longer at the address given, but assuming conservatively that all subjects not contacted were living at the correct address, adjusted response rates were $59.0 \%$ at baseline and $70.6 \%$ postintervention.

\section{Response rates}

The intervention and control groups had similar response rates which were highest among women and lowest among patients aged 20-29 years. Response rates differed greatly by practice (data not shown). The number of patients answering "yes" to any of the three screening questions was $1621(13.2 \%)$ in the baseline survey and $1616(15.0 \%)$ in the postintervention survey (table 1).

In the first and second surveys respectively we estimated the total number of patients with asthma in intervention practices at 5500 and 6500 (average 6000 ), and the numbers of patients taking drugs for asthma at 3500 and 4400 (average 3950). The practice nurses saw 1031 patients, and the average time of contact was 19 minutes.

\section{Effects on quality of life}

The mean quality of life after the intervention was similar between control (2.68) and intervention practices (2.64) (table 2): a high score indicated poor quality of life and a score of 2.5 corresponded to an average answer of mildly to the 20 quality of life questions (none, mildly, moderately, severely, very severely). We found evidence of clustering of mean square root quality of life among patients in the same practice in 
the baseline survey (intraclass correlation coefficient $0.0169, \mathrm{P}=0.007)$ but not in the postintervention survey $(0.0035, \mathrm{P}=0.26)$. We found no evidence for any difference between intervention and control practices even after we restricted analyses to patients taking drugs for their asthma, nor in further analyses that controlled for age, sex, mean practice square root quality of life in the first survey, and number of partners in the practice. We obtained similar results after allowing for the pairing of the practices and further restricting analyses to patients with a quality of life score of $\geq 5$.

Of the 1621 patients identified as asthmatic in the baseline survey, 1291 were still registered with a study practice at the postintervention survey and were sent a repeat questionnaire. All were asked to complete the asthma quality of life questionnaire. Overall, 468 responded (61.4\%) in control practices and 312 $(58.9 \%)$ in intervention practices; $351(75.0 \%)$ and 236 $(75.6 \%)$ were still classed as asthmatic respectively. Patients' square root quality of life measured at baseline and postintervention were strongly correlated $(\mathrm{r}=0.65)$. Table 3 shows the results of random effects regression models (allowing for clustering by practice at baseline) comparing mean square root quality of life in intervention and control practices. We found no evidence of a difference in mean square root quality of life from the crude model. However, after controlling for age, sex, and baseline square root quality of life, there was weak evidence for a reduction (improvement) in mean square root quality of life in intervention compared with control practices $(-0.066,-0.141$ to $0.009, \mathrm{P}=0.08$ ).

\section{Effects on delivery of asthma care}

We found no clear evidence that the intervention altered the delivery of asthma care (table 4). Among patients newly surveyed postintervention, those taking drugs for their asthma were no more likely to possess a steroid inhaler in the intervention practices or to remember having had an explanation of appropriate action from a doctor or nurse. For patients identified as asthmatic during the baseline survey there were strong associations between the responses to the questions at baseline and postintervention. After controlling for baseline response there was a tendency for more patients in intervention practices to have a steroid inhaler, a peak flow meter, or to remember being given an asthma plan, but confidence intervals were wide.

Among 694 subjects registered with study practices there were 1256 recorded attendances for asthma at accident and emergency departments. Average attendance rates over the study period (1 June 1993 to 30 September 1996) per 1000 person years in the control and intervention practices were 3.65 and 3.91 respectively. We confirmed the absence of any divergence in rates over the study period by random effects Poisson regression with robust standard errors.

Admissions data were available from April 1994. There were 220 admissions for asthma among 156 patients registered with study practices in the study age range. Average admission rates per 1000 person years over the study in the control and intervention practices were 0.86 and 0.91 respectively. We found no evidence of a divergence in rates over time.

Figure 3 shows trends in the prescribing of steroids in intervention and control practices, using the total
Table 1 Responses to asthma screening questions in baseline and postintervention surveys (24 400 patients each). Values are number (percentage) unless stated otherwise

\begin{tabular}{lcc} 
Variable & Baseline survey & $\begin{array}{c}\text { Post intervention } \\
\text { survey }\end{array}$ \\
\hline Patients responding & $12238(50.2)$ & $10783(44.2)$ \\
\hline Answered no to each question (not asthmatic) & $10617(86.8)$ & $9170(85.0)$ \\
\hline Waking with shortness of breath & $488(4.0)$ & $421(3.9)$ \\
\hline Asthma attack & $63(0.5)$ & $68(0.6)$ \\
\hline Currently taking drugs for asthma & $235(1.9)$ & $306(2.8)$ \\
\hline Waking with shortness of breath and asthma attack & $36(0.3)$ & $33(0.3)$ \\
\hline $\begin{array}{l}\text { Waking with shortness of breath and currently taking drugs } \\
\text { for asthma }\end{array}$ & $132(1.1)$ & $111(1.0)$ \\
\hline Asthma attack and currently taking drugs for asthma & $259(2.1)$ & $286(2.7)$ \\
\hline All of the above & $408(3.3)$ & $391(3.6)$ \\
\hline Patients considered asthmatic & $1621(13.2)$ & $1616(15.0)$ \\
\hline
\end{tabular}

Table 2 Quality of life among respondents with asthma in post intervention survey, based on number of patients with quality of life information

\begin{tabular}{|c|c|c|c|}
\hline Variable & $\begin{array}{l}\text { Mean quality of } \\
\text { life }(95 \% \mathrm{CI})\end{array}$ & $\begin{array}{l}\text { Mean square root quality } \\
\text { of life }(95 \% \mathrm{CI})\end{array}$ & $\begin{array}{l}\text { No }(\%) \text { of patients with } \\
\text { quality of life score } \geqslant 5\end{array}$ \\
\hline Control practices $(n=903)$ & 2.68 (2.52 to 2.84$)$ & 1.50 (1.46 to 1.54$)$ & $116(12.9)$ \\
\hline Intervention practices $(\mathrm{n}=659)$ & 2.64 (2.51 to 2.78$)$ & 1.52 (1.47 to 1.56$)$ & $95(14.4)$ \\
\hline $\begin{array}{l}\text { Difference in mean square root } \\
\text { quality of life }(95 \% \mathrm{CI})^{*}\end{array}$ & & $\begin{array}{c}-0.0095(0.105 \text { to } 0.086) \\
P=0.85\end{array}$ & \\
\hline $\begin{array}{l}\text { Difference in mean square root } \\
\text { quality of life for patients taking } \\
\text { asthma drugs }(95 \% \mathrm{Cl})^{*}\end{array}$ & & $\begin{array}{c}-0.009(-0.110 \text { to } 0.129) \\
P=0.88\end{array}$ & \\
\hline $\begin{array}{l}\text { Odds ratio }(95 \% \mathrm{Cl}) \text { comparing } \\
\text { intervention and control } \\
\text { practices } \dagger\end{array}$ & & & $\begin{array}{c}1.07(0.76 \text { to } 1.52) \\
P=0.68\end{array}$ \\
\hline
\end{tabular}

*Allowing for clustering by practice using random effects model.

†Allowing for clustering by practice using generalised estimating equations.

Table 3 Postintervention mean square root quality of life among respondents identified as asthmatic during baseline survey

\begin{tabular}{lcc} 
Variable & Control practices & Intervention practices \\
\hline Mean square root quality of life $(95 \% \mathrm{Cl})$ & $1.47(1.41$ to 1.52$)$ & $1.46(1.38$ to 1.54$)$ \\
\hline Difference in mean square root quality of life & $-0.003(-0.121$ to 0.115$), P=0.96$ \\
\hline $\begin{array}{l}\text { Controlling for baseline square root quality of } \\
\text { life, age, sex, and single partner practices }\end{array}$ & $-0.066(-0.14$ to 0.009$), P=0.08$ \\
$\begin{array}{l}\text { Restricting to individuals in the same practice at } \\
\text { baseline and post intervention }\end{array}$ & $-0.060(-0.141$ to 0.015$), P=0.11$ \\
$\begin{array}{l}\text { Restricting to individuals taking asthma drugs } \\
\text { post intervention }\end{array}$ & $-0.084(-0.172$ to 0.003$), P=0.06$ \\
\hline
\end{tabular}

${ }^{*}$ Allowing for clustering by practice using random effects model.

practice population aged $15-50$ years as the denominator. Steroid prescribing rates rose steadily during the study period. Rates of steroid prescribing were initially similar, but rose slightly faster in intervention than control practices. The average annual increase in steroid prescribing rates was 3\% per year higher in intervention than control practices $(-1 \%$ to $6 \%$, $\mathrm{P}=0.10)$. Analyses using steroid-bronchodilator ratios gave similar results: these were initially higher in control practices but converged as the study progressed.

\section{Discussion}

We showed no difference in asthma related quality of life after an intervention to improve asthma management in primary care. Although there was weak evidence of an effect in asthmatic patients registered with study practices throughout the study this was small and clinically unimportant. Prescribing of inhaled steroids tended to increase more rapidly in the 
Table 4 Responses to questions on asthma care among patients identified as asthmatic in post intervention survey

\begin{tabular}{|c|c|c|c|}
\hline \multirow[b]{2}{*}{ Variable } & \multicolumn{2}{|c|}{ No/total no $(\%)$ of patients } & \multirow[b]{2}{*}{ Odds ratio $(95 \% \mathrm{Cl})^{*}$} \\
\hline & Control practices & $\begin{array}{c}\text { Intervention } \\
\text { practices }\end{array}$ & \\
\hline \multicolumn{4}{|c|}{ Patients newly surveyed after intervention } \\
\hline \multicolumn{4}{|l|}{ Possession of steroid inhaler: } \\
\hline All patients & $448 / 870(51.5)$ & $332 / 627(53.0)$ & $1.07(0.87$ to 1.31$)$ \\
\hline Patients taking asthma drugs & $409 / 586(69.8)$ & $314 / 426(73.7)$ & 1.24 (0.94 to 1.62$)$ \\
\hline \multicolumn{4}{|l|}{ Possession of peak flow meter: } \\
\hline All patients & $251 / 880(28.5)$ & 139/623 (22.3) & $0.78(0.49$ to 1.24$)$ \\
\hline Patients taking asthma drugs & $237 / 602(39.3)$ & $137 / 431(31.8)$ & 0.85 (0.51 to 1.41$)$ \\
\hline \multicolumn{4}{|c|}{ Explanation of appropriate actions if asthma symptoms worsen: } \\
\hline All patients & $365 / 869(42.0)$ & $235 / 628(37.4)$ & $0.81(0.64$ to 1.01$)$ \\
\hline Patients taking asthma drugs & $309 / 600(51.5)$ & $209 / 438(47.7)$ & 0.85 (0.66 to 1.09$)$ \\
\hline \multicolumn{4}{|c|}{ Patients identified as asthmatic during first survey } \\
\hline \multicolumn{4}{|l|}{ Possession of steroid inhaler: } \\
\hline All patients & $241 / 450(53.6)$ & $171 / 298(57.4)$ & $1.09(0.78$ to 1.53$)$ \\
\hline Patients taking asthma drugs & $213 / 266(80.1)$ & $152 / 184(82.6)$ & $1.03(0.63$ to 1.66$)$ \\
\hline \multicolumn{4}{|l|}{ Possession of peak flow meter: } \\
\hline All patients & $139 / 443(31.4)$ & $91 / 302(30.1)$ & $1.24(0.83$ to 1.83$)$ \\
\hline Patients taking asthma drugs & 128/268 (47.8) & $88 / 189(46.6)$ & $1.18(0.75$ to 1.86$)$ \\
\hline \multicolumn{4}{|c|}{ Explanation of appropriate actions if asthma symptoms worsen: } \\
\hline All patients & $170 / 445(38.2)$ & $129 / 293(44.0)$ & $1.25(0.92$ to 1.70$)$ \\
\hline Patients taking asthma drugs & $146 / 277(52.7)$ & $120 / 189(63.5)$ & $1.41(0.85$ to 2.34$)$ \\
\hline
\end{tabular}

${ }^{*}$ Allowing for clustering between practices using generalised estimating equations and controlling for age, sex, single partner practices. Analyses for patients newly surveyed postintervention also control for practice log odds for question in baseline survey, whereas analyses for patients identified as asthmatic during first survey also control for response to question at baseline.

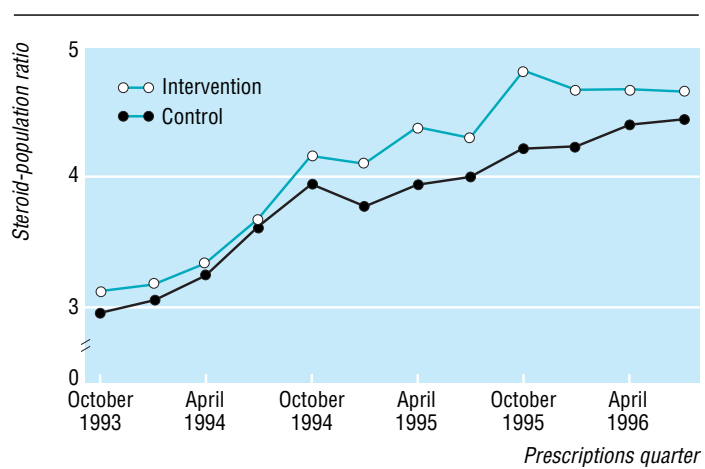

Fig 3 Ratio of total steroid prescriptions to practice population, by quarter

intervention practices $(\mathrm{P}=0.1)$, but there were no changes in the use of accident and emergency departments or inpatient services for asthma in the period.

Our study had sufficient power to detect even minor changes in the primary outcome. The asthma quality of life questionnaire has been validated ${ }^{18} 19$ and is known to be sensitive to change. The failure of the intervention was corroborated by the lack of improvement in all the secondary outcomes. Understanding why this intervention did not improve asthma care is important as it contained many of the characteristics that underpin current thinking on the improvement of care for asthmatic patients. It was based in primary care with a central role for practice nurses, and it was integrated across primary and secondary care.

\section{Comparison with other intervention studies}

Several studies have now shown an improvement in the management of asthmatic patients using a similar educational approach. The potentially important difference in our study is that we attempted to deliver the intervention to a whole district rather than to selected patients. The nurses saw an estimated $26 \%$ of the patients registered with intervention practices and taking drugs for their asthma: the proportion of all patients defined as asthmatic (which includes those with undiagnosed symptoms) was around $17 \%$.

\section{Self management versus improved prescribing}

In the original asthma resource centre protocol the main focus was on the development of self management plans. For nearly all the patients, regular and correct use of preventive drugs was as much in the way of self management as could be achieved in the limited time available, and the initial emphasis had to be reset to a simpler objective of increasing the use of anti-inflammatory treatment. This probably explained the lack of effect of intervention on the use of peak flow meters and management plans for exacerbations, but it does not explain the lack of success with inhaled steroids or lack of effect on quality of life.

In previous studies showing success of educational interventions, the control groups did not have their treatment optimised whereas the intervention group were educated about the use of asthma drugs and the inhaler delivery systems. ${ }^{7-92021}$ In one other trial ${ }^{22}$ where an effect was not shown, both the control and intervention groups were stabilised on steroid drugs before the educational intervention, suggesting that it is use of steroids and not other aspects of management that were effective in the other trials. Charlton et $\mathrm{al}^{4}$ failed to identify whether it was the self management plans, the use of peak flow meters, the increased number of patient contacts, or the nurses that had the greatest impact on improving patients' morbidity.

\section{High staff turnover}

The practice nurse changed in 12 of the 18 practices during the study, which was unexpected and led to a less effective education service for patients. Nurse specialists often covered for absent practice nurses. However, of the 13 practice nurses taught by the asthma resource centre who were in post at the end of the project, 11 passed a fairly rigorous assessment of their competence. We conclude that the asthma resource centre probably achieved its target in educating the practice nurses.

\section{Patients with less severe disease}

On average, the severity of asthma among our subjects was lower than in some clinic or hospital based studies. This may have made it more difficult to detect a change in quality of life. Restricting the analysis to patients with more severe disease, however, did not change this conclusion. Focusing attention on these patients during the intervention might, nevertheless, have achieved better results.

\section{Other influences on prescribing}

Use of steroids increased in both groups of practices, slightly more in the intervention practices. During the study, the Family Health Service Authority had targeted underuse of steroid inhalers, and this initiative may explain some of the increase although use of steroids was also increasing nationally at this time. This may imply that there are more effective ways of increasing the use of recommended drugs than the 
- Small randomised trials suggest that implementation of management guidelines can improve outcomes for asthmatic patients treated in specialist units

- Randomised trials also suggest that guidelines can improve the process of care in general practice

- An intervention in which specialist nurses trained and supported practice nurses in running asthma clinics on the basis of British Thoracic Society guidelines failed to improve asthma outcomes for patients over a 3 year period

- Factors that may have reduced the potential impact of the measures include the large number of asthmatic patients that need to be cared for in primary care, and the high turnover of practice nurses in inner city areas

- Further research is required on how best to implement good practice in inner city areas if cost effective interventions are to be devised

establishment of an asthma resource centre. According to the health survey for England ${ }^{23}$ almost all asthmatic patients see a doctor for asthma related problems whereas comparatively few see practice nurses. It may be that a model bypassing the doctor is inappropriate for improving general practice based asthma management. However, increasing steroid prescribing without educating patients about their proper use is not sufficient.

\section{Conclusions}

These results are important for implementing government policy. Despite considerable efforts, with three nurse specialists working for 3 years with half the practice nurses in the catchment area of a district general hospital, the study failed to show improvement in the quality of life of the asthmatic population in general, with evidence of at most a small effect in asthmatic patients who were identified during the baseline survey. The programme could possibly have been improved by concentrating on the more severely ill patients, and using group education to maximise the use of resources, and by making the doctors more central to the programme. Either way current policies for improving health care for asthmatic patients should be reviewed and alternative models evaluated at community level.

We thank the general practices of Greenwich, the patients who took part in this study, the staff of the asthma resource centre, and the steering committee of the asthma resource centre: Dr P J Rees (chairman) who commented on an earlier draft of the paper, Miss Julie Simpson who gave advice during the design of the study, and Miss Ruth Dundas and Mr Stephen Phillips who helped with data management. Peter Mullender of Greenwich and Bexley Health Authority provided prescribing information, Francis Phillips and Sue Sitch provided lists of patients, and Oliver Smith of Greenwich Healthcare provided information on attendances at accident and emergency departments and hospital admissions.

Contributors: JRW developed the asthma resource centre. PGJB and GBM designed the evaluation. GBM and UNP coordinated the study at different times. Data collection and data organisation was undertaken by UNP, HA, and JACS. The analysis was undertaken by JACS. All the authors participated in writing the paper. PGJB and JACS will act as guarantors for the paper.

Funding: Medical Research Council. The asthma resource centre was funded by the South Thames Primary Care Development Fund.

1 British Thoracic Society. Guidelines on the management of asthma Statement by the British Thoracic Society, the British Paediatric Association, the Research Unit of the Royal College of Physicians of London, the King's Fund Centre, the National Asthma Campaign, the Roval College of General Practitioners, the General Practitioners in Asthma Group, the British Association of Accident and Emergency Medicine, and the British Paediatric Respiratory Group. Thorax $1993 ; 48: 1-24 S$

2 British Thoracic Society. The British guidelines on asthma management-1995 review and position statement. Thorax 1997;52:1-21S.

3 Department of Health. Terms of service for doctors in general practice. London: $\mathrm{DoH}, 1990$.

4 Charlton I, Charlton G, Broomfield J, Mullee MA. Audit of the effect of a nurse run asthma clinic on workload and patient morbidity in a general practice. Br J Gen Pract 1991;41:227-31

5 Charlton I, Charlton G, Broomfield J, Campbell M. An evaluation of a nurse-run asthma clinic in general practice using an attitudes and morbidity questionnaire. Fam Pract 1992;9:154-60.

6 Meijer RJ, Kerstjens HA, Postma DS. Comparison of guidelines and selfmanagement plans in asthma. Eur Respir J 1997;10:1163-72.

7 Wilson SR, Scamagas P, German DF, Hughes GW, Lulla S, Coss S, et al. A controlled trial of two forms of self-management education for adults with asthma. Am J Med 1993;94:564-76.

8 Yoon R, McKenzie DK, Bauman A, Miles DA. Controlled trial evaluation of an asthma education programme for adults. Thorax 1993;48:1110-6.

9 Ignacio-Garcia JM, Gonzalez-Santos P. Asthma self-management education program by home monitoring of peak expiratory flow. Am J Resp Crit Care Med 1995; 151:353-9.

10 Lahdensuo A, Haahtela T, Herrala J, Kava T, Kiviranta K, Kuusisto P, et al. Randomised comparison of guided self management and traditional treatment of asthma over one year. BMJ 1996;312:748-52.

11 Allen RM, Jones MP, Oldenburg B. Randomised trial of an asthma self-management programme for adults. Thorax 1995;50:731-8.

12 Jones KP, Mullee MA, Middleton M, Chapman E, Holgate ST. Peak flow based asthma self-management: a randomised controlled study in general practice. British Thoracic Society Research Committee. Thorax 1995;50:851-7.

13 Feder G, Griffiths C, Highton C, Eldridge S, Spence M, Southgate L. Do clinical guidelines introduced with practice based education improve care of asthmatic and diabetic patients? A randomised controlled trial in general practices in east London. BMJ 1995;311:1473-8.

14 Marks GB, Burney PG, Premaratne UN, Simpson J, Webb J. Asthma in Greenwich, UK: impact of the disease and current management practices. Eur Respir J 1997;10:1224-9.

15 Marks GB, Dunn SM, Woolcock AJ. A scale for the measurement of quality of life in adults with asthma. J Clin Epidemiol 1992;45:461-72.

16 Premaratne UN, Marks GB, Austin EJ, Burney PGJ. A reliable method to retrieve accident and emergency data stored on a free-text basis. Respi Med 1997;91:61-6.

17 Liang K-Y, Zeger SL. Longitudinal data analysis using generalised linear models. Biometrika 1986;73:13-22.

18 Marks GB, Dunn SM, Woolcock AJ. An evaluation of an asthma quality of life questionnaire as a measure of change in adults with asthma. J Clin Epidemiol 1993;46:1103-11.

19 Gupchup GV, Wolfgang AP, Thomas J III. Reliability and validity of the asthma quality of life questionnaire-marks in a sample of adult asthma patients in the United States. Clin Ther 1997;19:1116-25.

20 Bailey WC, Richards JM Jr, Brooks CM, Soong SJ, Windsor RA, Manzella BA. A randomized trial to improve self-management practices of adults with asthma. Arch Intern Med 1990;150:1664-8.

21 Mayo PH, Richman J, Harris HW. Results of a program to reduce admissions for adult asthma. Ann Intern Med 1990;112:864-71.

22 Cote J, Cartier A, Robichaud P, Boutin H, Malo J-L, Rouleau M, et al Influence on asthma morbidity of asthma education programs based on self-management plans following treatment optimization. Am J Respir Crit Care Med 1997; 155:1509-14.

23 Prescott-Clarke P, Primatosta P (eds). Health survey for England, Vol 1. London: Stationery Office, 1996;51-2. [Tables 2.18 and 2.19.] (Accepted 7 April 1999)

\section{Endpiece}

\section{Gender}

$\mathrm{n}$. Is a grammatical term only. To talk of persons or creatures of the masculine or feminine $g$., meaning of the male or female sex, is either a jocularity (permissible or not according to context) or a blunder.

The New Fowler's Modern English Usage (1996) 